\title{
Acute Myeloblastic Leukemia in Paroxysmal Nocturnal Hemoglobinuria Evidence of Evolution from the Abnormal Paroxysmal Nocturnal Hemoglobinuria Clone
}

Dana V. Devine,* W. Larry Gluck, Wendell F. Rosse, and J. Brice Weinberg

*Department of Microbiology and Immunology and Departments of Medicine, Duke University Medical Center, and Veterans Administration Medical Center, Durham, North Carolina 27710

\begin{abstract}
Paroxysmal nocturnal hemoglobinuria (PNH) is an acquired hematopoietic stem cell disorder in which the blood cells demonstrate aberrant interactions with serum complement. In part, this is due to the absence of the complement regulatory protein, decay accelerating factor (DAF). A small number of patients with PNH have gone on to develop acute nonlymphocytic leukemia, which is thought to arise from the injured marrow as a second hematopoietic disorder. We have studied a patient with PNH who developed acute myeloblastic leukemia (AML); the blasts from this patient were found to lack DAF as measured by polyclonal antibody binding and fluorescence flow cytometry as well as by immunoblotting. The blasts from 11 other patients with AML bound anti-DAF antibody in amounts similar to normal mononuclear cells from healthy donors. Cells of the human leukemia cell lines HL-60, K562, U937, and HEL also bound anti-DAF antibody. In addition to DAF deficiency, blasts from the PNH patient had undetectable alkaline phosphatase activity, in contrast to human leukemia cell lines. These data suggest that the leukemic cells of the PNH patient arose out of the PNH clone and that AML in the setting of PNH is not a separate disorder.
\end{abstract}

\section{Introduction}

Paroxysmal nocturnal hemoglobinuria $(\mathrm{PNH})^{1}$ is a clonal dyshematopoietic stem cell disorder characterized by cells that are unusually susceptible to the hemolytic action of complement, reduced hematopoiesis in many patients, and a propensity for acute leukemia. The clonal nature of PNH is suggested by the presence of populations of cells with normal, moderate, or marked susceptibility to lysis by complement (1) and is demonstrated by analysis of the isozymes of glucose-6-phosphate dehydrogenase in the populations of erythrocytes; abnormal cells of patients who are heterozygous for different isozymes possess

Address reprint requests to Dr. Devine, Box 3934, Duke University Medical Center, Durham, NC 27710.

Received for publication 14 July 1986.

1. Abbreviations used in this paper: AML, acute myeloid leukemia; DAF, decay accelerating factor; FITC, fluorescein isothiocyanate; PAGE, polyacrylamide gel electrophoresis; $\mathrm{PNH}$, paroxysmal nocturnal hemoglobinuria; SPA, staphylococcal protein A.

J. Clin. Invest.

(c) The American Society for Clinical Investigation, Inc.

0021-9738/87/01/0314/04 \$1.00

Volume 79, January 1987, 314-317 a single isozyme whereas the more normal cells possess both isozymes (2).

All of the abnormal cells in PNH (PNH II and PNH III cells) lack decay accelerating factor (DAF), a protein that regulates the activity of the $\mathrm{C} 3$ amplification steps of complement activation (3-6). The more abnormal erythrocytes (PNH III cells) have an additional undefined defect that increases the effectiveness of the membrane attack complex of complement (7-9). In addition, two defects are known that do not appear to be related to the sensitivity of the cells to complement: both PNH II and PNH III erythrocytes lack the enzyme, acetylcholinesterase (10), and PNH neutrophils lack activity of the enzyme alkaline phosphatase (11).

The development of acute nonlymphocytic leukemia is uncommon; 11 patients have been previously reported (12) and, among our $\sim 80$ patients with PNH, three (not reported) have developed this complication. When leukemia occurs, the abnormal erythrocytes often disappear; this has been interpreted to mean that the marrow is replaced by a second abnormal, leukemic clone.

In this paper, we present data on a patient with PNH who developed acute leukemia. The blasts of this patient were shown to have been derived from the same clone as the abnormal erythrocytes in that both blasts and erythrocytes lacked DAF, whereas the blasts of leukemic patients who had not had PNH had quantities of this protein on the blasts equivalent to the amounts on mature normal cells.

In addition, the blasts of this patient, like PNH neutrophils, lacked alkaline phosphatase, again in contrast to the blasts of other patients with acute leukemia $(13,14)$ and human leukemic cell lines. Since both of these membrane proteins, as well as acetylcholinesterase, which is deficient in PNH erythrocytes, are affixed to the membrane through a phosphatidylinositol-dependent linkage (15), these findings suggest that the fundamental defect in PNH may have to do with the abnormal synthesis or degradation of membrane proteins with this type of linkage.

\section{Methods}

Cells and reagents. Blood samples from healthy volunteer donors or consenting patients were anticoagulated with heparin or EDTA. The mononuclear cells were separated by centrifugation through lymphocyte separation medium (Litton Bionetics, Kensington, MD) according to the manufacturer's recommendations and washed three times with phosphate-buffered saline containing $10 \mathrm{mM}$ EDTA (PBS-EDTA). Differential cell counts were performed on stained cytopreps of these mononuclear cell preparations. Some patient blasts had been cryopreserved in liquid nitrogen with dimethylsulfoxide after isolation. These cells were thawed, washed twice in Dulbecco's minimal essential medium without serum, then once in PBS-EDTA immediately before testing. 
The complement lysis sensitivity test of Rosse and Dacie (1) was used to measure the percentage of abnormal erythrocytes in the peripheral blood of the PNH patient. The patient was maintained on chronic transfusion therapy and had 3-16\% PNH III erythrocytes in the peripheral blood from the time the diagnosis of acute myeloblastic leukemia (AML) was made until he died.

K562 (16) and U937 (17) cells were the generous gift of Dr. Donna Kostyu, Department of Microbiology and Immunology, Duke University Medical Center. HEL (18), HL-60 (19), and HL-60 BII (20) cells were grown in this laboratory. All leukemia cell lines were washed in PBSEDTA immediately before testing.

Rabbit antiserum to DAF was raised in this laboratory using DAF purified from erythrocyte membranes (21). Staphylococcal protein A (SPA, Sigma Chemical Co., St. Louis, MO) was labeled with ${ }^{125}$ I (Amersham Corp., Arlington Heights, IL) using Iodogen (Pierce Chemicals, Rockford, IL).

Leukocyte alkaline phosphatase activity. Alkaline phosphatase activity was determined by the method of Sommer (22) using p-nitrophenyl phosphate (Sigma Chemical Co.) as a substrate. The cells were dissolved in $0.05 \%$ Triton X-100 for use in the assay. Results are expressed as nanomoles $p$-nitrophenol $/ 10^{7}$ cells $/ 2 \mathrm{~h}$.

Flow cytometry analysis of DAF. Cells prepared as described above were suspended in PBS-EDTA at a concentration of $4 \times 10^{6} / \mathrm{ml}$. The cells were incubated first with an equal volume of nonimmune rabbit serum or rabbit anti-DAF at a saturating dilution of 1:500 for $30 \mathrm{~min}$ at room temperature. After three washes in PBS-EDTA, the cells were incubated in fluorescein isothiocyanate (FITC) labeled $F\left(a b^{\prime}\right)_{2}$ goat antirabbit IgG (Jackson Immunoresearch, Avondale, PA) for 30 min, washed twice and fixed in $1 \%$ formalin.

The cell-associated fluorescence was monitored using an Ortho 50 H cytofluorograph with an Ortho 2140 data handling system (Ortho Diagnostics, Raritan, NJ). Analysis was restricted to signals from single cells and amplifiers were set in linear mode. For statistical analysis, regions were set using the nonimmune serum treated cells as negative controls.

Detection of DAF by immunoblotting. Washed HL-60 or U937 cells or myeloblasts from the PNH patient $\left(1 \times 10^{6}\right.$ cells $)$ were solubilized and the proteins were separated by discontinuous SDS polyacrylamide gel electrophoresis (PAGE) in a 7.5\% resolving gel (23). The proteins were electrophoretically transferred to nitrocellulose paper according to the method of Towbin et al. (24). After blocking with Tris-saline containing 3\% bovine serum albumin (BSA), the nitrocellulose paper was incubated first with either nonimmune rabbit serum or rabbit anti-DAF antiserum and second with ${ }^{125}$ I-labeled SPA. The paper was dried and autoradiography performed.

\section{Results}

Flow cytometry analysis of the binding of nonimmune serum and anti-DAF to the blasts of the PNH patient, normal donor mononuclear cells, and blasts from two representative AML patients are seen in Fig. 1. Anti-DAF showed significant binding to normal donor cells (Fig. $1, A$ ) as well as to the cells of AML patients who did not have PNH. However, anti-DAF failed to bind to the blasts of the PNH patient (Fig. 1, B). Nine other AML patients whose blasts were assayed for anti-DAF binding had from 69 to 99\% DAF-positive cells (Table I). The abnormal erythrocytes of the PNH patient also failed to bind anti-DAF antibody (data not shown).

The human leukemia cell lines HL-60, HL-60 BII, U937, HEL, and K562 all bound anti-DAF antibody (Table I). The staining patterns of three of these cell lines are shown in Fig. 2. When analyzed by fluorescence flow cytometry, HEL cells appeared to have a heterogeneous antigen distribution, while the staining pattern of K562 cells was similar to that of HL-60 and U937 cells.

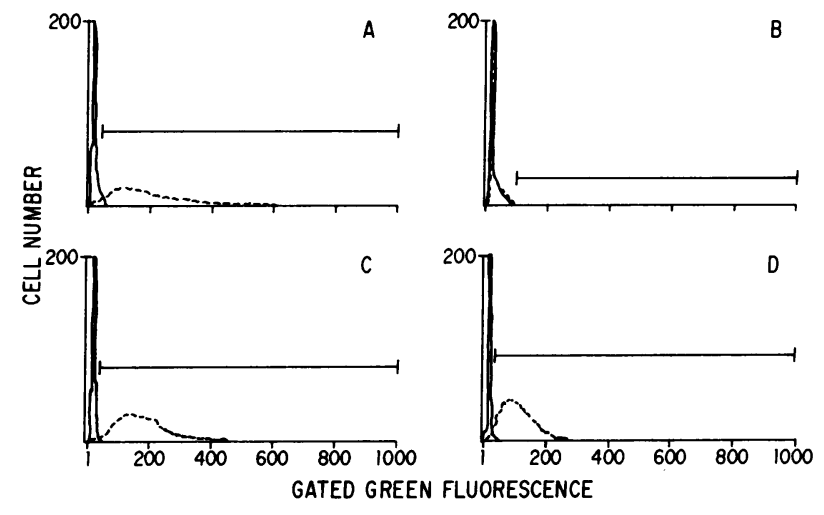

Figure 1. Flow cytometry analysis of anti-DAF binding to mononuclear cells. Cells were first incubated either with nonimmune rabbit serum (solid lines) or rabbit anti-DAF (dashed lines), then with fluorescein-labeled $\mathrm{F}\left(\mathrm{ab}^{\prime}\right)_{2}$ goat anti-rabbit IgG. The staining patterns are shown for normal mononuclear cells $(A)$, myeloblasts from the patient with PNH $(B)$, and myeloblasts from patients with AML, which were either freshly isolated $(C)$ or cryopreserved $(D)$. Cells appearing in channels shown under the bar were considered to be positive for antiDAF binding.

When U937 cells, HL-60 cells, and the PNH patient's blasts were assayed for DAF by immunoblotting, the two leukemia cell lines both had a protein band of $\sim 70 \mathrm{kD}$ that reacted with the anti-DAF antiserum, but not with nonimmune serum (Fig. 3). However, the PNH patient blasts did not contain immunoreactive DAF.

Table I. Fluorescence Flow Cytometry Analysis of DAF on Myeloblasts from Patients with $A M L$ and on Cells from Human Leukemia Cell Lines

\begin{tabular}{clll}
\hline & Diagnosis & Blasts* & DAF-positive cells \\
\hline & & $\%$ & $\%$ \\
Patient & & & \\
1. & PNH/AML & 100 & 3 \\
2. & AML & 32 & 87 \\
3. & AML & 99 & 96 \\
4. & AML & 90 & 98 \\
5. & AML & 90 & 90 \\
6. & AML & 87 & 69 \\
7. & AML & 67 & 84 \\
8. & AML & 12 & 91 \\
9. & AML & 31 & 95 \\
10. & AML & 79 & 98 \\
11. & AML & 96 & 99 \\
12. & AML & 90 & 94 \\
Cell lines & & & \\
HL-60 & & & 83 \\
HEL & & & 99 \\
U937 & & & 85 \\
K562 & & & 95 \\
HL-60 BII & & & \\
Healthy donors $(n=8)$ & & &
\end{tabular}

* Determined from Wright stained cytoprep of isolated mononuclear cells. 

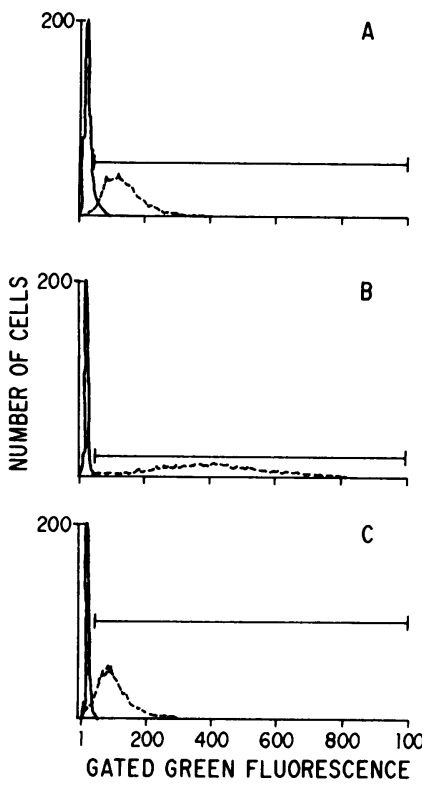

Figure 2. Flow cytometry analysis of anti-DAF binding to human leukemia cell lines. Cells were incubated first with nonimmune rabbit serum (solid lines) or rabbit anti-DAF (dashed lines), then with fluorescein-labeled $\mathrm{F}\left(\mathrm{ab}^{\prime}\right)_{2}$ goat anti-rabbit IgG. Shown are the staining patterns for U937 cells $(A)$, HEL cells $(B)$, and HL-60 cells $(C)$. Cells appearing in channels shown under the bar were considered to be positive for anti-DAF binding.
Alkaline phosphatase activity was measured in HL-60, HL60 BII, U937, and K562 cells as well as in peripheral blood polymorphonuclear leukocytes, the PNH patient's blasts and the blasts of AML patients. In comparison to the cell lines, peripheral blood leukocytes, and AML patient blasts, the PNH patient's blasts had undetectable alkaline phosphatase activity (Table II).

\section{Discussion}

Acute leukemia is occasionally seen in patients with PNH (12), but it is not known whether the leukemic cells arise from the abnormal PNH clone or from another clone in a damaged marrow. Because the population of abnormal erythrocytes diminishes or disappears in most patients previously reported with the development of leukemia (12), it has been thought that the leukemia arises from a separate clone. The present studies demonstrate that in this patient, the leukemic cell line arose from the PNH line because the cells lack decay accelerating factor, an abnormality characteristic of PNH.

The expression of DAF by all the blasts of patients with AML as well as all the human leukemic cell lines studied extends the known cellular distribution of DAF to include representatives of the myeloid series other than fully differentiated peripheral

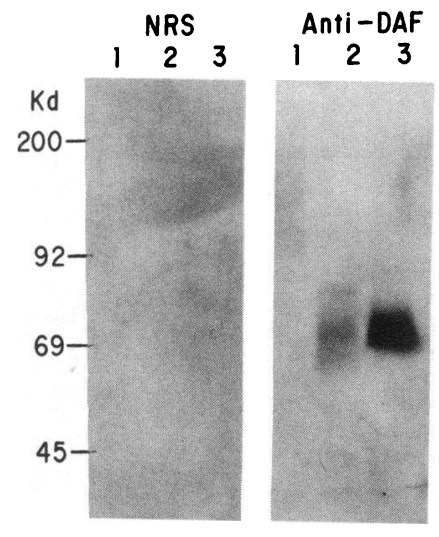

Figure 3. Immunoblot analysis of DAF. Proteins from $1 \times 10^{6}$ PNH patient myeloblasts (1), HL-60 cells (2), or U937 cells (3) were separated by SDSPAGE and transferred to nitrocellulose paper. The nitrocellulose was then incubated with nonimmune rabbit serum (NRS) or rabbit anti-DAF antiserum followed by ${ }^{125}$ I-labeled protein A.
Table II. Alkaline Phosphatase Activity of Cells from Human Leukemia Cell Lines, Peripheral Blood Leukocytes, and Blasts from the PNH Patient

\begin{tabular}{lc}
\hline Cell type & Alkaline phosphatase activity \\
\hline & nmol p-nitrophenol/10 $0^{\prime}$ cells/2 $h$ \\
HL-60 & $6.3 \pm 1.4$ \\
K562 & $26.1 \pm 4.1$ \\
HL-60 BII & $36.0 \pm 6.6$ \\
U937 & $9.6 \pm 0.4$ \\
AML patient blasts & \\
1. & $3.6 \pm 0.6$ \\
2. & $12.2 \pm 1.7$ \\
3. & $8.7 \pm 3.2$ \\
4. & $15.6 \pm 2.1$ \\
PNH patient blasts & No detectable activity \\
Neutrophils & $30.4 \pm 2.6$
\end{tabular}

Assays were performed as described in the text. Results are expressed as the mean $>3$ assays \pm 1 SD.

blood elements (6). The DAF detected by immunoblot of U937 and HL-60 cells had an apparent relative mobility very similar to that described for DAF on normal peripheral blood cells (6). Although studies of DAF expression by myeloid progenitors do not exist, normal erythroid progenitors (erythroid burst-forming units, BFU-E) have been found to express DAF (25). These data along with the data presented here suggest that DAF expression occurs early in cellular differentiation, which perhaps reflects the important role of DAF in the restriction of complement activation on the surface of autologous cells.

Leukocyte alkaline phosphatase is lacking in some mature granulocytes of patients with PNH. The blasts from this patient also lacked alkaline phosphatase, whereas AML blasts from patients who have not had PNH contain alkaline phosphatase activity similar in amount to that of the human leukemia cell line blasts. The coincidence of DAF and alkaline phosphatase deficiency in the blasts of this patient indicates that these cells are characteristic of the abnormal cells in PNH.

In addition to DAF and alkaline phosphatase, the abnormal blood cells in PNH lack erythrocyte acetylcholinesterase (10). These three membrane proteins share the unusual characteristic of being bound to the cell membrane by a phosphatidylinositoldependent linkage (15). The underlying defect in PNH may be one that affects the synthesis or degradation of this family of proteins.

\section{Acknowledgments}

We thank Frank Cornew for performing the cytofluorography, Mary Misukonis for technical assistance, Dr. John Hunter, Wilmington, NC, for referring the patient to us, and Dr. Joseph Moore for help in procuring samples from AML patients.

Supported in part by National Institutes of Health grant 1 R01 AM31379, and the Veterans Administration and the James Swiger Hematology Research Fund.

\section{References}

1. Rosse, W. F., and J. V. Dacie. 1966. Immune lysis of normal human and paroxysmal nocturnal hemoglobinuria (PNH) red blood cells. 
I. The sensitivity of PNH red cells to lysis by complement and specific antibody. J. Clin. Invest. 45:736-744.

2. Oni, S. B., B. O. Osunkoya, and L. Luzzatto. 1970. Paroxysmal nocturnal hemoglobinuria. Evidence for monoclonal origin of abnormal red cells. Blood. 36:145-152.

3. Nicholson-Weller, A., J. P. March, S. I. Rosenfield, and K. F. Austen. 1983. Affected erythrocytes of patients with paroxysmal nocturnal hemoglobinuria are deficient in the complement regulatory protein, decay accelerating factor. Proc. Natl. Acad. Sci. USA. 80:5066-5070.

4. Pangburn, M. K., R. D. Schreiber, and H. J. Muller-Eberhard. 1983. Deficiency of an erythrocyte membrane protein with complement regulatory activity in paroxysmal nocturnal hemoglobinuria. Proc. Natl. Acad. Sci. USA. 80:5430-5434.

5. Nicholson-Weller, A., D. B. Spicer, and K. F. Austen. 1985. Deficiency of the complement regulatory protein, "decay accelerating factor", on membranes of granulocytes, monocytes, and platelets in paroxysmal nocturnal hemoglobinuria. N. Engl. J. Med. 321:1091-1097.

6. Kinoshita, T., M. E. Medof, R. Silber, and V. Nussenzweig. 1985. Distribution of decay-accelerating factor in the peripheral blood of normal individuals and patients with paroxysmal nocturnal hemoglobinuria. $J$. Exp. Med. 162:75-92.

7. Roualt, T. A., W. F. Rosse, S. Bell, and J. Shelburne. 1978. Differences in the terminal steps of complement lysis of normal and paroxysmal nocturnal hemoglobinuria red cells. Blood. 51:325-330.

8. Gotze, O., and H. J. Muller-Eberhard. 1970. Lysis of erythrocytes by complement in the absence of antibody. J. Exp. Med. 132:898-915.

9. Parker, C. J., T. Wiedmer, P. J. Sims, and W. F. Rosse. 1985. Characterization of the complement sensitivity of paroxysmal nocturnal hemoglobinuria erythrocytes. J. Clin. Invest. 75:2074-2084.

10. Chow, F. L., M. J. Telen, and W. F. Rosse. 1985. The acetylcholinesterase defect in paroxysmal nocturnal hemoglobinuria: evidence that the enzyme in absent from the cell membrane. Blood. 66:940-945.

11. Craddock, P. R., J. Fehr, and H. S. Jacob. 1976. Complementmediated granulocyte dysfunction in paroxysmal nocturnal hemoglobinuria. Blood. 47:931-939.

12. Krause, J. R. 1983. Paroxysmal nocturnal hemoglobinuria and acute non-lymphocytic leukemia. A report of three cases exhibiting different cytologic types. Cancer. 51:2078-2082.

13. Kramers, M. T. C., D. Catovsky, and R. Foa. 1978. Cell membrane enzymes II. Alkaline phosphatase and alkaline phosphodiesterase I in normal and leukemic lymphocytes. Br. J. Haematol. 40:111-118.
14. Hultberg, B., and U. Sjogren. 1980. Diagnostic significance of lysosomal enzymes in different types of leukemias. Acta Med. Scand. 207:105-110.

15. Davitz, M. A., M. G. Low, and V. Nussenzweig. 1986. Release of decay-accelerating factor (DAF) from the cell membrane by phosphatidylinositol-specific phospholipase C (PIPLC). J. Exp. Med. 163: $1150-1161$.

16. Lozzio, B., and C. Lozzio. 1979. Properties and usefulness of the original K562 human myelogenous leukemia cell line. Leukemia Res. 3:363-370.

17. Sundstrom, C., and K. Nilsson. 1976. Establishment and characterization of a human histiocytic lymphoma cell line (U-937). Int. J. Cancer 17:565-577.

18. Martin, P., and T. Papayannopoulou. 1982. HEL cells: A new human erythroleukemia cell line with spontaneous and induced globin expression. Science (Wash. DC). 216:1233-1235.

19. Gallagher, R., E. Collins, J. Trujillo, K. McCredic, M. Ahearn, S. Tsai, R. Metzgar, G. Aulakh, R. Ting, F. Ruscetti, and R. Gallo. 1979. Characterization of the continuous differentiating myeloid line (HL-60) from a patient with acute promyelocytic leukemia. Blood. 54:713-733.

20. Major, P. P., J. D. Griffin, M. Minden, and D. W. Kufe. 1981. A blast subclone of the HL-60 human promyelocytic cell line. Leukemia Res. 5:429-430.

21. Nicholson-Weller, A., J. Burge, D. T. Fearon, P. F. Weller, and K. F. Austen. 1982. Isolation of a human erythrocyte membrane glycoprotein with decay-accelerating activity for the $\mathrm{C} 3$ convertases of the complement system. J. Immunol. 129:184-189.

22. Sommer, A. J. 1954. The determination of acid and alkaline phosphatase using p-nitrophenyl phosphate as substrate. Am. J. Med. Tech. 20:244-260.

23. Laemmli, U. K. 1970. Cleavage of structural proteins during the assembly of the head of bacteriophage T4. Nature (Lond.). 227:680-685.

24. Towbin, H., T. Staehlin, and J. Gordon. 1979. Electrophoretic transfer of proteins from polyacrylamide gels to nitrocellulose sheets: Procedure and some applications. Proc. Natl. Acad. Sci. USA. 76:32504354.

25. Moore, J. G., R. K. Humphries, M. M. Frank, and N. Young. 1986. Characterization of the hematopoietic defect in paroxysmal nocturnal hemoglobinuria. Exp. Hematol. 14:222-229. 